\title{
Prevalence of cervical human papillomavirus infection in women with systemic lupus erythematosus
}

\author{
Leomar D. C. Lyrio · Maria Fernanda R. Grassi · Iuri U. Santana • Viviana G. Olavarria • \\ Aline do N. Gomes $\cdot$ Licia CostaPinto $\cdot$ Rone Peterson C. Oliveira • \\ Rita de Cássia R. Aquino • Mittermayer B. Santiago
}

Received: 20 December 2011 / Accepted: 11 March 2012 / Published online: 27 March 2012

(C) Springer-Verlag 2012

\begin{abstract}
Genital infection by human papillomavirus (HPV) tends to occur more frequently in patients with conditions associated with immune suppression. Systemic lupus erythematosus (SLE) is an immunological disorder characterized by generalized inflammation and a number of clinical manifestations and circulating autoantibodies. The aim of the present study was to determine the prevalence of genital HPV infection among female SLE patients. Women diagnosed with SLE based on American College of Rheumatology classification criteria followed at rheumatology outpatient clinic of the Escola Bahiana de Medicina e Saude Publica, Salvador, Brazil, were included in the study. As a comparison group, clinically healthy women who were attending the gynecology outpatient clinic for routine examination at the same institution were recruited. Testing for cervical HPV infection was performed using the nested polymerase chain reaction technique. Eighty-eight female SLE patients (mean age, $41.4 \pm 11.6$ years) and seventy healthy female subjects (control group) were studied. The prevalence of HPV infection was $80.7 \%(71 / 88)$ in the SLE group and $35.7 \%(25 / 70)$ in the control group
\end{abstract}

L. D. C. Lyrio - I. U. Santana · V. G. Olavarria · A. d. N. Gomes ·

L. CostaPinto $\cdot$ R. P. C. Oliveira $\cdot$ R. C. R. Aquino ·

M. B. Santiago ( $\square)$

Escola Bahiana de Medicina e Saúde Pública,

Rua Frei Henrique, 08, Nazaré, Salvador,

Bahia CEP 40000-000, Brazil

e-mail:mitter@svn.com.br

M. F. R. Grassi

Centro de Pesquisa Gonçalo Moniz/Fundação

Oswaldo Cruz, Salvador, Bahia, Brazil

M. B. Santiago

Serviços especializados em Reumatologia (SER) da Bahia,

Salvador, Brazil $(p<0.0001)$. After adjustment of the variables (early sexual activity, number of partners and obstetric history), the odds ratio (OR) for genital HPV infection in women with SLE was 7.2 (95\% CI, 2.9 to $17.8 ; p=0.0001)$. The use of immunosuppressive drugs was not associated with a higher prevalence of HPV infection. This study demonstrated that SLE patients have a higher prevalence of genital HPV infection, even when exposed to less potential risk factors for the virus.

Keywords Human papillomavirus - Systemic lupus erythematosus - Polymerase chain reaction .

Immunosuppression $\cdot$ Cervical cancer

\section{Introduction}

The human papillomavirus (HPV) is composed of a group of DNA viruses of the family papoviridae. More than 200 types of HPV can infect humans, and the anogenital region is the most commonly affected [1]. This type of virus can be divided into two groups: low-oncogenic HPV, which is represented primarily by types 06 and 11 , and high-oncogenic HPV, which commonly refer to types 16 and 18 . Case-control studies confirm that the HPV DNA can be detected in $99.7 \%$ of women with histologically confirmed cervical cancer, as opposed to $13.4 \%$ of controls [2]. The presence of HPV is a necessary element, but not the only component required for the development of cervical cancer.

The potential risk factors for cervical HPV infection are the following: age between 20 and 24, early sexual activity, multiple sexual partners, tobacco use, pregnancy, poor nutritional state, history of sexual transmitted diseases (STDs) such as genital herpes and Chlamydia trachomatis [3]. Immunosuppression is also an important risk factor [4-6]. 
Systemic lupus erythematosus (SLE) is a systemic autoimmune disease of unknown origin, characterized by chronic inflammation and diverse clinical manifestations as well as by the presence of different autoantibodies. Although SLE can occur at any age, it is more frequent among people between the ages of 20 and 45 with the highest incidence occurring in individuals around the age of 30 and affects 10-12 times as many women as men. Individuals with SLE are generally immunosuppressed by the disease itself or by the use of medications which inhibit the immune system [6]. The normal defense mechanisms against oncogenic viruses are therefore compromised in these patients, and theoretically, there is an increased risk of cervical abnormalities in them. The objective of this study was to determine the prevalence of cervical HPV infection and evaluate the presence of cervical lesions in women with SLE, in comparison with a group of clinically healthy women.

\section{Materials and methods}

This study is a cross-sectional analysis of the prevalence of cervical HPV infection in women with SLE. A group of women diagnosed with SLE and a control group of clinically healthy women followed in rheumatology and gynecology clinics, respectively, at the Escola Bahiana de Medicina e Saúde Pública were included in the study. The diagnosis of SLE was based upon the American College of Rheumatology classification criteria [7]. Inclusion criteria for the study were over 18 years of age and sexually active. Exclusion criteria were psychiatric disorders, having undergone total hysterectomy, and pregnancy. This study was approved by the research Ethics Committee of our Institution. All patients freely signed informed consent forms before agreeing to take part in the study.

The patients responded to a structured questionnaire that evaluated sociodemographic, behavioral, rheumatological and gynecological/obstetric aspects of their lives. After the interview, physical and gynecological examinations were carried out. Specimens for Papanicolaou smears were collected from ectocervix and endocervix using an Ayres spatula and cytobrush, respectively. Squamous cell abnormalities seen in the Papanicolaou smears were classified as low-grade or high-grade squamous intraepithelial lesions, in accordance with the 2001 Bethesda System [8]. Colposcopic examinations were carried out in all of the women by the gynecologist. If a lesion was indicated by the colposcopy or cytology results, it was further evaluated by means of biopsies, which were examined and classified in accordance with the CIN system [9]. Cytological samples were collected from the ecto- and endocervices for HPV testing, using sterile swabs. The cervical sample was transported in $400 \mu \mathrm{l}$ of TE [ $10 \mathrm{mM}$ Tris- $\mathrm{HCl} \mathrm{pH} 8.0$ and $1 \mathrm{mM}$ ethylenediaminetetraacetic acid
(EDTA)] and stored at $-20{ }^{\circ} \mathrm{C}$. DNA extraction was performed using the commercial QIAamp ${ }^{\circledR}$ DNA Mini Kit (QIAGEN, Germany), according to the manufacturer's protocol. The samples were frozen at $-20{ }^{\circ} \mathrm{C}$ until used. These samples were analyzed using the polymerase chain reaction (PCR) technique in the Advanced Laboratory of Public Health (LASP) of FIOCRUZ in Salvador, Brazil. For DNA amplification, it was used the nested PCR (n-PCR) method, as suggested by Demathe et al. [10] with some modification. For the first round, it was used the MY09/11 consensus outer primer pair, capable of amplifying a 450 base pair fragment directed to a highly conserved region of the viral protein $\mathrm{L} 1$. In the second round, it was used the GP5+/GP6+ consensus inner primer pairs to amplify a 150 base pair fragment, restrained in the 450 base pair fragment amplified previously. The amplification reaction used a standard system for each round of the reaction containing a final volume of $12.5 \mu \mathrm{l}$. The first round was composed of $1.25 \mu$ of the PCR buffer $(10 \times), 0.4 \mu \mathrm{l}$ of $\mathrm{MgCl} 2(50 \mathrm{mM}), 2 \mu \mathrm{l}$ of dNTP $(1.25 \mathrm{mM})$, $0.3 \mu \mathrm{l}$ of Taq DNA polymerase $(5 \mathrm{U} / \mu \mathrm{l}), 1 \mu \mathrm{l}$ of each outer primer $(10 \mathrm{pmol} / \mu \mathrm{l}), 5.5 \mu \mathrm{l}$ of water and $1 \mu \mathrm{l}$ of DNA template $(50-100 \mathrm{ng} / \mu \mathrm{l})$. The amplification was performed using an Applied Biosystems Veritas ${ }^{\mathrm{TM}}$ Thermal Cycler with the following cycling temperatures: initial heating at $94{ }^{\circ} \mathrm{C}$ for $1 \mathrm{~min}, 40$ cycles of denaturation at $95^{\circ} \mathrm{C}$ for $1 \mathrm{~min}$, annealing at $55^{\circ} \mathrm{C}$ for $1 \mathrm{~min}$ and extension at $72^{\circ} \mathrm{C}$ for $1 \mathrm{~min}$, followed by a final extension at $72^{\circ} \mathrm{C}$ for $5 \mathrm{~min}$. The second round was performed using Top Taq Master Mix Kit (QIAGEN, Germany), consisting of $6.5 \mu \mathrm{l}$ of TopTaq Master Mix $(2 \times), 1.3 \mu \mathrm{l}$ of each inner primer $(50 \mathrm{pmol} / \mu \mathrm{l}), 1.3 \mu \mathrm{l}$ of Coral Load Concentrate $(10 \times), 1.1 \mu \mathrm{l}$ of water and $1 \mu \mathrm{l}$ of the first round PCR product. The amplification was performed with the following cycling temperatures: initial heating at $94{ }^{\circ} \mathrm{C}$ for $4 \mathrm{~min}, 35$ cycles of denaturation at $94{ }^{\circ} \mathrm{C}$ for $1 \mathrm{~min}$, annealing at $40{ }^{\circ} \mathrm{C}$ for $2 \mathrm{~min}$ and extension at $72{ }^{\circ} \mathrm{C}$ for 1 and a half minutes, followed by final extension for $72{ }^{\circ} \mathrm{C}$ for $4 \mathrm{~min}$. To avoid false-negative results, an additional PCR was performed using a primers pair capable of amplifying a region of 268 base pairs of human $\beta$-globin protein. The PCR product was detected using agarose gel electrophoresis $(2 \%)$ and stained with ethidium bromide. The positive and negative controls were samples analyzed using the cobas ${ }^{\circledR} 4800$ HPV Test, provided by the DNA Laboratory, Salvador-Bahia. Internal negative control, prepared with the same reagents, replacing the DNA template by water was also used.

The $95 \%$ confidence interval (CI) was established to estimate the prevalence of HPV in this population, and $p$ value $\leq 0.05$ was considered statistically significant. The categorical variables are expressed in absolute values and percentages, and the quantities are described in mean and standard deviation. Pearson's chi-squared test and Fischer's exact test were used to compare the categorical variables 
between the two groups. Student's $t$ test was used to compare continuous variables between the two groups, taking into consideration the parametric distribution of the studied samples, confirmed by the histogram and by congruence between the mean and median. The association between SLE and HPV infection was investigated taking into account known potential risk factors for genital infection by this virus. The odds ratio $(\mathrm{OR})$ was determined adjusting the variables that were at least moderately associated with HPV infection. Statistical analysis was carried out using SPSS software (Statistical Package for the Social Sciences), version 17.0.

\section{Results}

The SLE group was composed of 88 patients with a mean age of $41.4 \pm 11.6$ years, older than the control group of 70 clinically healthy women $(29.0 \pm 5.9$ years $)(p<0.0001)$. The mean age at first sexual intercourse was at $19.9 \pm 4.9$ years among SLE patients and $17.6 \pm 4.1$ years in the control group $(p=0.002)$. The number of sexual partners was slightly lower in women with SLE $(2.8 \pm 2.2)$ than in the control group $(3.79 \pm 4.5)$; however, this difference was not statistically significant. The prevalence of HPV cervical infection was $80.7 \%(71 / 88)$ in the SLE group and $35.7 \%$ in the control group $(p<0.0001)$ (Table 1$)$. The OR for HPV infection in women with SLE was $7.1(95 \% \mathrm{CI}$; $2.9-17.7 ; p=0.0001$ ) after the following variables were adjusted: age, start of sexual activity, number of sexual partners, condom use and obstetric history (Table 2).

There was no statistically significant difference between the two groups with regard to cytological abnormalities: LGSIL, HGSIL and ASC-US. However, normal cytopathological results were less commonly observed in the SLE group $(1 / 71$ or $1.4 \%)$ than in the control group $(5 / 25$ or $20 \%) ; p<0.0004$ (Table 3). Regarding risk factors associated with cervical HPV infection in the group of SLE patients, condom use was less prevalent in the group of patients with cervical HPV infection $(9.9 \%)$ than in the group of patients who tested negative for HPV (29.4\%); $p=0.03$. There was no statistically significant difference with relation to the age at first sexual intercourse, number of sexual partners, time of the diagnosis of SLE or the use of immunosuppressive drugs (defined as the use during any period of the illness of any of the following immunosuppressive drugs: azathioprine, methotrexate, cyclophosphamide, cyclosporine, mycophenolate mofetil, or mycophenolate sodium) (Table 4). However, abnormal colposcopic findings were more frequent in women with SLE who were infected by HPV and used immunosuppressive drugs ( 12 or $24.5 \%$ ) than they were in the group that did not use immunosuppressive drugs ( 1 or $4.5 \%) p=0.05$ (Table 5).
Table 1 Sociodemographic characteristics, sexual history and cervical HPV prevalence in patients with SLE and in clinically healthy women

\begin{tabular}{lllc}
\hline & $\begin{array}{l}\text { SLE group } \\
(n=88)\end{array}$ & $\begin{array}{l}\text { Control group } \\
(n=70)\end{array}$ & $p$ value \\
\hline $\begin{array}{l}\text { Age (years) } \\
\text { Household Income }\end{array}$ & $41.4 \pm 11.6$ & $29.0 \pm 5.9$ & $<0.0001$ \\
$\begin{array}{l}\text { At or below one } \\
\quad \text { minimum wage }\end{array}$ & $49(54.4 \%)$ & $33(47.1 \%)$ & 0.35 \\
$\quad$ Two or more & $41(45.6 \%)$ & $37(52.9 \%)$ & \\
$\quad$ minimum wages & & & \\
Education* & & & \\
$\leq 8$ years & $35(41.7 \%)$ & $24(34.3 \%)$ & \\
Between 8 and 11 years & $39(46.4 \%)$ & $31(44.3 \%)$ & \\
Over 12 years & $10(11.9 \%)$ & $15(21.4 \%)$ & \\
Age at first sexual & $19.9 \pm 4.9$ & $17.6 \pm 4.1$ & 0.002 \\
$\quad$ intercourse (years $)$ & & & \\
Number of sexual partners & $2.8 \pm 2.2$ & $3.79 \pm 4.5$ & 0.09 \\
Parity & $1.7 \pm 1.9$ & $1.3 \pm 1.2$ & 0.11 \\
Abortions & $0.7 \pm 1.1$ & $0.5 \pm 0.9$ & 0.37 \\
Condom use & $14(15.6 \%)$ & $12(17.1 \%)$ & 0.78 \\
HPV infection & $71(80.7 \%)$ & $25(35.7 \%)$ & $<0.0001$ \\
\hline
\end{tabular}

Data are presented as mean and standard deviation for continuous variables and $n(\%)$ for categorical variables

SLE systemic lupus erythematosus, HPV human papillomavirus

* Data obtained from 84 SLE patients

Table 2 Odds ratio (OR) adjusted for potential risk factors for HPV infection

\begin{tabular}{lllc}
\hline Variables & Adjusted OR & $95 \%$ CI & $p$ value \\
\hline SLE & 7.1 & $2.9-17.7$ & $<0.0001$ \\
Age & 1.0 & $0.9-1.0$ & 0.55 \\
Age at first sexual intercourse & 0.9 & $0.8-1.0$ & 0.51 \\
Number of partners & 0.9 & $0.8-1.1$ & 0.87 \\
Condom use & 0.5 & $0.2-1.6$ & 0.31 \\
Parity & 0.8 & $0.6-1.1$ & 0.28 \\
\hline
\end{tabular}

SLE Systemic lupus erythematosus, $H P V$ Human papillomavirus, $C I$ confidence interval

\section{Discussion}

Data in the literature consistently demonstrate that women with SLE are at increased risk of the development of cervical cytological abnormalities [11-13]. However, few studies confirm the molecular diagnosis of cervical HPV infection [11, 14]. HPV infection can precede the development of cytological abnormalities by years, making the persistence of the virus in the tissue an important risk factor for the progression of cellular changes. 
Table 3 Pap smear findings in patients with SLE and in clinically healthy women with cervical HPV infection

\begin{tabular}{lccc}
\hline & $\begin{array}{l}\text { SLE group } \\
(n=71)\end{array}$ & $\begin{array}{l}\text { Control group } \\
(n=25)\end{array}$ & $p$ value \\
\hline LGSIL & $11(15.5 \%)$ & $2(8.0 \%)$ & 0.50 \\
HGSIL & $3(4.2 \%)$ & $0(0 \%)$ & 0.56 \\
IP & $48(67.6 \%)$ & $18(72.0 \%)$ & 0.68 \\
Normal & $1(1.4 \%)$ & $5(20 \%)$ & 0.004 \\
ASC-US & $3(4.2 \%)$ & $0(0 \%)$ & 0.56 \\
Abnormal & $13(18.3 \%)$ & $3(12 \%)$ & 0.22 \\
$\quad$ Pap smear & & & \\
\hline
\end{tabular}

Data are presented as $n(\%)$ for categorical variables

LGSIL low-grade squamous intraepithelial lesion, HGSIL high-grade squamous intraepithelial lesion, IP inflammatory process, ASC-US atypical squamous cells of undetermined significance, $S L E$ systemic lupus erythematosus, $H P V$ human papillomavirus

Table 4 Possible risk factors for HPV infection in patients with SLE

\begin{tabular}{|c|c|c|c|}
\hline & $\begin{array}{l}\text { Infected } \\
\text { with HPV } \\
(n=71)\end{array}$ & $\begin{array}{l}\text { Not infected } \\
\text { with HPV } \\
(n=17)\end{array}$ & $p$ value \\
\hline Age & $42.1 \pm 12.3$ & $40.2 \pm 5.9$ & 0.55 \\
\hline Household income & & & 0.96 \\
\hline $\begin{array}{l}\text { At or below one } \\
\text { minimum wage }\end{array}$ & $38(53.5 \%)$ & $9(52.9 \%)$ & \\
\hline $\begin{array}{l}\text { Two or more } \\
\text { minimum wages }\end{array}$ & $33(46.5 \%)$ & $8(47.1 \%)$ & \\
\hline Education* & & & 0.62 \\
\hline$\leq 8$ years & $30(44.1 \%)$ & $5(31.3 \%)$ & \\
\hline Between 8 and 11 years & $30(44.1 \%)$ & $9(56.3 \%)$ & \\
\hline Over 12 years & $8(11.8 \%)$ & $2(12.5 \%)$ & \\
\hline $\begin{array}{l}\text { Age at first sexual } \\
\text { intercourse }\end{array}$ & $20.2 \pm 5.1$ & $18.7 \pm 3.9$ & 0.24 \\
\hline Number of sexual partners & $2.8 \pm 2.2$ & $2.8 \pm 2.4$ & 0.97 \\
\hline Condom use & $7(9.9 \%)$ & $5(29.4 \%)$ & 0.03 \\
\hline $\begin{array}{l}\text { Use of immunosuppressive } \\
\text { drugs }\end{array}$ & $49(69 \%)$ & $9(52.9 \%)$ & 0.20 \\
\hline $\begin{array}{l}\text { Time of last gynecological } \\
\text { evaluation }\end{array}$ & $1.6 \pm 1.7$ & $1.9 \pm 1.9$ & 0.58 \\
\hline
\end{tabular}

Data are presented as mean and standard deviation for continuous variables and $n(\%)$ for categorical variables

SLE systemic lupus erythematosus, $H P V$ human papillomavirus

* Results for the group with HPV are based on $n=68$, results for the group without HPV are based on $n=16$

This study demonstrated a higher prevalence of cervical HPV infection in women with SLE when compared with clinically healthy women, despite less exposure to potential risk factors for HPV among the group of women with SLE (older age, greater age at first sexual intercourse, and smaller number of sexual partners than the control group). In a multivariate logistic regression model, the presence of
Table 5 Association between the use of immunosuppressive drugs and Pap smear abnormalities in patients with SLE infected by HPV

\begin{tabular}{|c|c|c|c|}
\hline Pap smear & $\begin{array}{l}\text { Immunosuppressive* } \\
+(n=49)\end{array}$ & $\begin{array}{l}\text { Immunosuppressive } \\
-(n=22)\end{array}$ & $p$ value \\
\hline LGSIL & $9(18.4 \%)$ & $2(9.1 \%)$ & 0.48 \\
\hline HGSIL & $2(4.1 \%)$ & $1(4.5 \%)$ & 1.00 \\
\hline IP & $32(65.3 \%)$ & $16(72.7 \%)$ & 0.53 \\
\hline Normal & $0(0 \%)$ & $1(4.5 \%)$ & 0.31 \\
\hline ASC-US & $3(6.1 \%)$ & $0(0.0 \%)$ & 0.54 \\
\hline $\begin{array}{l}\text { Abnormal } \\
\text { Pap smear }\end{array}$ & $12(24.5 \%)$ & $1(4.5 \%)$ & 0.05 \\
\hline
\end{tabular}

Data are presented as $n(\%)$ for categorical variables

LGSIL low-grade squamous intraepithelial lesion, HGSIL high-grade squamous intraepithelial lesion, IP inflammatory process, ASC-US atypical squamous cells of undetermined significance, SLE systemic lupus erythematosus, $H P V$ human papillomavirus

* Immunosuppressive drugs: azathioprine, methotrexate, cyclophosphamide, cyclosporine, mycophenolate mofetil, or mycophenolate sodium

SLE was an independent predictor for HPV infection. The prevalence of cervical HPV infection found in women with SLE was greater than what has been described in the literature. Tam et al. (China) observed a prevalence of $11.8 \%$ [11], while Nath et al. (United Kingdom) found a prevalence of $54 \%$ [14]. This difference can be attributed to diagnostic techniques used. In the cited studies, HPV infection was demonstrated by simple PCR, using only one consensus primer pair. In this study, the n-PCR technique was used, which combines two different pairs of consensus primers. The advantage of this last technique is the substantial increase in sensitivity $[10,15]$. However, we cannot exclude the possible contribution of still undefined genetic factors in the different populations studied.

Women with SLE are more prone to infection by different etiologic agents than are the clinically healthy population [16]. This greater susceptibility can be explained by the different intrinsic abnormalities of the disease, associated with the use of immunosuppressive therapy [17]. Patients with SLE have defective mechanisms that are involved with the innate immune response, such as inappropriate activation of Toll-like receptors for self-antigens, decreased clearance of apoptotic bodies, deficiency of mannose-binding lectin and complement deficiency. Further, SLE patients have many abnormalities in their adaptive immune responses, with a loss of self-tolerance in $\mathrm{T}$ and $\mathrm{B}$ lymphocytes and the production of various antibodies against self-antigens, as well as the lower production of certain cytokines. These immunological abnormalities are associated with an elevated risk of bacterial infections. Similarly, different types of viral infections seem to be more common in these patients [18]; this is the case with Parvovirus B19 infection [19, 20], cytomegalovirus [21], 
varicella-zoster virus [22], Epstein--Barr virus [23] and herpes simplex virus [24]. These immune disorders also seem to be associated with an increased risk of cervical HPV infection, with more tissue persistence and the development of malignant lesions. It is thus assumed that cervical HPV infection in these patients tends to spontaneously resolve itself less frequently than it does in healthy women.

Regarding immunosuppressive drugs, there is still no consensus in the literature as to whether or not the use of these drugs is associated with a higher prevalence of cervical HPV infection in women with SLE. Some studies associate the use of azathioprine [25] and cyclophosphamide [6, 26] with a higher prevalence of cervical HPV infection in women with SLE. The same phenomenon was observed in patients without lupus who used azathioprine after renal transplantation [27]. However, this association was not observed by other authors $[11,12]$. In this study the use of immunosuppressive drugs was not associated with a greater prevalence of cervical HPV infection in women with SLE. Nevertheless, this finding should be interpreted cautiously as the number of SLE patients who did not use immunosuppressive drugs was relatively low. Curiously, in SLE patients infected by HPV, it was observed that those who used immunosuppressive drugs had a higher incidence of abnormal colposcopic findings than those who did not use the drugs. However, the cross-sectional nature of the study did not allow for the patients to be monitored and the eventual evolution to cervical cancer.

In conclusion, the results of this study indicate that women with SLE have a higher incidence of cervical HPV infection than the control group. This high prevalence was found despite the fact that the women with SLE had been exposed to fewer potential risk factors for HPV. Therefore, we recommend that patients with lupus have regular gynecological evaluations, with shorter intervals in between examinations than the general population. Additionally, although not evaluated in the present study, perhaps the use of prophylactic HPV vaccines could be a valuable tool for these patients. However, studies are necessary to find out whether the efficacy of these vaccines could be modified due to immunosuppression imposed by the disease and/or by the drugs used for its treatment.

Acknowledgments M.S. receives a scholarship from the Conselho Nacional de Desenvolvimento Científico e Tecnológico (CNPq).

Conflict of interest The authors have no conflict of interest that is directly relevant to the content of this manuscript.

\section{References}

1. Lizano M, Berumen J, Garcia-Carranca A (2009) HPV-related carcinogenesis: basic concepts, viral types and variants. Arch Med Res 40(6):428-434
2. Munoz N (2000) Human papillomavirus and cancer: the epidemiological evidence. J Clin Virol 19(1-2):1-5

3. Veldhuijzen NJ, Snijders PJ, Reiss P, Meijer CJ, van de Wijgert JH (2010) Factors affecting transmission of mucosal human papillomavirus. Lancet Infect Dis 10(12):862-874

4. Grinsztejn B, Veloso VG, Levi JE, Velasque L, Luz PM, Friedman RK et al (2009) Factors associated with increased prevalence of human papillomavirus infection in a cohort of HIV-infected Brazilian women. Int J Infect Dis 13(1):72-80

5. Santana IU, Gomes AD, Lyrio LD, Rios Grassi MF, Santiago MB (2011) Systemic lupus erythematosus, human papillomavirus infection, cervical pre-malignant and malignant lesions: a systematic review. Clin Rheumatol 30(5):665-672

6. Ognenovski VM, Marder W, Somers EC, Johnston CM, Farrehi JG, Selvaggi SM et al (2004) Increased incidence of cervical intraepithelial neoplasia in women with systemic lupus erythematosus treated with intravenous cyclophosphamide. J Rheumatol 31(9):1763-1767

7. Tan EM, Cohen AS, Fries JF, Masi AT, McShane DJ, Rothfield NF et al (1982) The 1982 revised criteria for the classification of systemic lupus erythematosus. Arthritis Rheum 25(11):12711277

8. Solomon D, Davey D, Kurman R, Moriarty A, O'Connor D, Prey $\mathrm{M}$ et al (2002) The 2001 Bethesda system: terminology for reporting results of cervical cytology. JAMA 287(16):2114-2119

9. Richart RM (1990) A modified terminology for cervical intraepithelial neoplasia. Obstet Gynecol 75(1):131-133

10. Demathe A, Bernabé DG, Garcia JF, Nunes CM, Miyahara GI (2010) Comparação entre dois métodos de detecção de DNA de papilomavírus humano em carcinoma epidermoide de lábio. J Bras Patol Med Lab 46:85-90

11. Tam LS, Chan AY, Chan PK, Chang AR, Li EK (2004) Increased prevalence of squamous intraepithelial lesions in systemic lupus erythematosus: association with human papillomavirus infection. Arthritis Rheum 50(11):3619-3625

12. Barros BRC, Matschinske R, Silva MB, Skare TL (2007) Prevalence of abnormal pap smears in patients with systemic lupus erythematosus. Rev Bras Reumatol 47(5):325-329

13. Dhar JP, Kmak D, Bhan R, Pishorodi L, Ager J, Sokol RJ (2001) Abnormal cervicovaginal cytology in women with lupus: a retrospective cohort study. Gynecol Oncol 82(1):4-6

14. Nath R, Mant C, Luxton J, Hughes G, Raju KS, Shepherd P et al (2007) High risk of human papillomavirus type 16 infections and of development of cervical squamous intraepithelial lesions in systemic lupus erythematosus patients. Arthritis Rheum 57(4):619625

15. Freitas TP, Carmo BB, Paula FD, Rodrigues LF, Fernandes AP, Fernandes PA (2007) Molecular detection of HPV 16 and 18 in cervical samples of patients from Belo Horizonte, Minas Gerais, Brazil. Rev Inst Med Trop Sao Paulo 49(5):297-301

16. Barber C, Gold WL, Fortin PR (2011) Infections in the lupus patient: perspectives on prevention. Curr Opin Rheumatol 23(4):358-365

17. Cuchacovich R, Gedalia A (2009) Pathophysiology and clinical spectrum of infections in systemic lupus erythematosus. Rheum Dis Clin North Am 35(1):75-93

18. Ramos-Casals M, Cuadrado MJ, Alba P, Sanna G, Brito-Zeron P, Bertolaccini $L$ et al (2008) Acute viral infections in patients with systemic lupus erythematosus: description of 23 cases and review of the literature. Medicine (Baltimore) 87(6):311-318

19. Pugliese A, Beltramo T, Torre D, Roccatello D (2007) Parvovirus B19 and immune disorders. Cell Biochem Funct 25(6):639-641

20. Aslanidis S, Pyrpasopoulou A, Kontotasios K, Doumas S, Zamboulis C (2008) Parvovirus B19 infection and systemic lupus erythematosus: activation of an aberrant pathway? Eur J Intern Med 19(5):314-318 
21. Su BY, Su CY, Yu SF, Chen CJ (2007) Incidental discovery of high systemic lupus erythematosus disease activity associated with cytomegalovirus viral activity. Med Microbiol Immunol 196(3):165-170

22. Pope JE, Krizova A, Ouimet JM, Goodwin JL, Lankin M (2004) Close association of herpes zoster reactivation and systemic lupus erythematosus (SLE) diagnosis: case-control study of patients with SLE or noninflammatory nusculoskeletal disorders. J Rheumatol 31(2):274-279

23. Kawashiri S, Nakamura H, Kawakami A, Ida H, Izumi Y, Tamai $\mathrm{M}$ et al (2006) Emergence of Epstein-Barr virus-associated haemophagocytic syndrome upon treatment of systemic lupus erythematosus. Lupus 15(1):51-53
24. Khamaganova IV (1992) Herpetic infection in patients with lupus erythematosus. Ter Arkh 64(11):121-123

25. Nyberg G, Eriksson O, Westberg NG (1981) Increased incidence of cervical atypia in women with systemic lupus erythematosus treated with chemotherapy. Arthritis Rheum 24(5):648-650

26. Bateman H, Yazici Y, Leff L, Peterson M, Paget SA (2000) Increased cervical dysplasia in intravenous cyclophosphamidetreated patients with SLE: a preliminary study. Lupus 9(7): 542-544

27. Kay S, Frable WJ, Hume DM (1970) Cervical dysplasia and cancer developing in women on immunosuppression therapy for renal homotransplantation. Cancer 26(5):1048-1052 